\title{
Biomechanical evaluation of the ProDisc-C stability following graded posterior cervical injury
}

\author{
Michael D. Staudt, MD, MSc, Doron Rabin, MD, ${ }^{2}$ Ali A. Baaj, MD, ${ }^{3}$ Neil R. Crawford, $\mathrm{PhD},{ }^{4}$ and \\ Neil Duggal, MD, MSc ${ }^{1}$
}

'Department of Clinical Neurological Sciences, London Health Sciences Centre, Western University, London, Ontario, Canada; ${ }^{2}$ St. Luke's University Health Network, Bethlehem, Pennsylvania; ${ }^{3}$ Department of Neurological Surgery, Weill Cornell Medical College, New York, New York; and "Barrow Neurological Institute, Spinal Biomechanics Laboratory, Phoenix, Arizona

\begin{abstract}
OBJECTIVE There are limited data regarding the implications of revision posterior surgery in the setting of previous cervical arthroplasty (CA). The purpose of this study was to analyze segmental biomechanics in human cadaveric specimens with and without $\mathrm{CA}$, in the context of graded posterior resection.

METHODS Fourteen human cadaveric cervical spines (C3-T1 or C2-7) were divided into arthroplasty (ProDisc-C, $n$ $=7$ ) and control (intact disc, $n=7$ ) groups. Both groups underwent sequential posterior element resections: unilateral foraminotomy, laminoplasty, and finally laminectomy. Specimens were studied sequentially in two different loading apparatuses during the induction of flexion-extension, lateral bending, and axial rotation.
\end{abstract}

RESULTS Range of motion (ROM) after artificial disc insertion was reduced relative to that in the control group during axial rotation and lateral bending $(13 \%$ and $28 \%$, respectively; $p<0.05)$ but was similar during flexion and extension. With sequential resections, ROM increased by a similar magnitude following foraminotomy and laminoplasty in both groups. Laminectomy had a much greater effect: mean (aggregate) ROM during flexion-extension, lateral bending, and axial rotation was increased by a magnitude of $52 \%$ following laminectomy in the setting of $\mathrm{CA}$, compared to an $8 \%$ increase without arthroplasty. In particular, laminectomy in the setting of CA introduced significant instability in flexionextension, characterized by a $90 \%$ increase in ROM from laminoplasty to laminectomy, compared to a $16 \%$ increase in ROM from laminoplasty to laminectomy without arthroplasty $(p<0.05)$.

CONCLUSIONS Foraminotomy and laminoplasty did not result in significant instability in the setting of $\mathrm{CA}$, compared to controls. Laminectomy alone, however, resulted in a significant change in biomechanics, allowing for significantly increased flexion and extension. Laminectomy alone should be used with caution in the setting of previous CA.

https://thejns.org/doi/abs/10.3171/2018.3.SPINE171248

KEYWORDS biomechanics; cervical arthroplasty; artificial cervical disc; graded resection; laminectomy; foraminotomy; laminoplasty; range of motion

$\mathrm{C}$ ERVICAL disc replacement will likely have a distinct role in the management of degenerative cervical disc disease. The consequences of injury, disease, and surgical decompression of the posterior cervical spine before or after the insertion of a cervical disc replacement have not been examined. Although a retrospective analysis of six patients with cervical arthroplasty (CA) following previous posterior foraminotomy demonstrated no devicerelated complications at $14.5-41.9$ months' follow-up, ${ }^{27}$ no clinical studies have reported outcomes after CA followed by more extensive resection. The biomechanical conse- quences on the functioning of an artificial disc in the setting of graded posterior column injury remain unknown.

In vitro studies of graded injury to the posterior elements of the cervical spine have demonstrated a clear impact on spinal stability and biomechanical parameters. ${ }^{13,31}$ Zdeblick et al. examined axial stiffness, torsional displacement, and posterior displacement under physiological loads in cadaveric cervical spines undergoing graded laminectomy and unilateral foraminotomies. ${ }^{31}$ Spinal hypermobility was evident following $75 \%$ or $100 \%$ unilateral facetectomy. Similarly, using a physiological flexion/

ABBREVIATIONS BMD = bone mineral density; $C A=$ cervical arthroplasty; $I A R=$ instantaneous axis of rotation; $L Z$ = lax zone; PLL = posterior longitudinal ligament; RM$\mathrm{ANOVA}=$ repeated-measures analysis of variance; $\mathrm{ROM}=$ range of motion; $\mathrm{SZ}$ = stiff zone.

SUBMITTED November 20, 2017. ACCEPTED March 29, 2018.

INCLUDE WHEN CITING Published online August 31, 2018; DOI: 10.3171/2018.3.SPINE171248. 
compression paradigm, Cusick et al. examined single segment motion following unilateral or bilateral total facetectomy. ${ }^{13}$ Angular motion of the vertebral body increased by approximately $4 \%$ and $10.7 \%$ in the unilateral facetectomy and bilateral facetectomy specimens, respectively. The impact of these biomechanical changes is uncertain in the context of an existing anterior cervical disc prosthesis.

Numerous in vitro biomechanical methods are used to test cervical disc replacements. ${ }^{1,6,8,26}$ Careful characterization of the range of motion (ROM), lax zone (LZ), and stiff zone (SZ) provides valuable information on whether the loading patterns on the soft tissues change at the index and adjacent levels after disc replacement. In the context of graded posterior spinal decompression, we performed paired and nonpaired comparisons of these parameters in human cadaveric specimens with an intact disc and following CA.

\section{Methods}

\section{Specimen Selection}

Fourteen human cadaveric $\mathrm{C} 3-\mathrm{T} 1$ or $\mathrm{C} 2-7$ specimens were studied ( 7 male and 7 female cadavers; mean age 55 years, range 45-64 years). The number of specimens used was chosen to be consistent with the numbers in similar studies. ${ }^{2,3,18,25,28}$ The condition of each specimen when received, especially the index level, dictated whether C3-T1 (index level C5-6) or C2-7 (index level C4-5) was used. That is, if manual palpation indicated equivalent flexibility at $\mathrm{C} 4-5$ and $\mathrm{C} 5-6$ or greater flexibility at C5-6, then C3T1 was harvested; if C4-5 appeared substantially more flexible than C5-6, then C2-7 was harvested. Specimens were obtained fresh frozen then thawed in a bath of normal saline at $30^{\circ} \mathrm{C}$ and were carefully cleaned of muscle tissue without damaging any ligaments, discs, or joint capsules. Plain film radiographs were obtained, and specimens with any obvious radiographic or visible flaws (i.e., advanced osteophytes, disc narrowing, or joint arthrosis) were excluded and replaced. Anteroposterior dual-energy x-ray absorptiometry scans were performed on the C5 vertebra of each specimen to assess bone mineral density (BMD). Specimens with scores indicating obvious osteoporosis were excluded and replaced. For testing purposes, household screws were inserted in the exposed vertebral body and facet articulations of T1 (or C7 in two specimens), and these screw heads were embedded in polymethylmethacrylate and attached to the base of the testing apparatus. The rostral half of C3 (or C2) was similarly potted in a metal fixture for the application of loads.

Testing commenced before receiving all 14 specimens. As new specimens were received, they were randomly assigned to two groups for testing, with the arthroplasty group undergoing disc replacement and the control group having an intact disc. At the beginning of the testing period, as a specimen was received, it was assigned to a group and tested through all steps so that equal numbers of each group had been tested to completion, preventing any bias caused by one group being tested with greater skill and experience (and hence shorter unrefrigerated exposure time) than the other group. Toward the end of the testing period, a more deliberate effort was made to separate incoming
TABLE 1. Sequence of conditions tested

\begin{tabular}{cl}
\hline \multicolumn{1}{c}{ Step No. } & \multicolumn{1}{c}{ Description } \\
\hline Arthroplasty group & \\
\hline 1 & Normal condition \\
\hline 2 & After disc replacement \\
\hline 3 & After foraminotomy \\
\hline 4 & After laminoplasty \\
\hline 5 & After laminectomy \\
\hline Control group & \\
\hline 1 & Normal condition \\
\hline 3 & After retesting normal condition \\
\hline 4 & After foraminotomy \\
\hline 5 & After laminoplasty \\
\hline
\end{tabular}

Each group had 7 specimens.

specimens into these two groups in such a way that age, $\mathrm{BMD}$, and sex would be kept equivalent to prevent bias caused by one group having greater innate stability. Statistically, the mean age was equivalent between the groups ( $p$ $=0.352$ ). However, there was a trend (not statistically significant) demonstrating higher BMD in the control group than in the arthroplasty group $(p=0.052)$. Within each group, specimens were nondestructively tested in 5 steps (Table 1).

\section{Specimen Preparation}

Disc replacement (step 2, arthroplasty group; Fig. 1A) was performed using the ProDisc-C (DePuy Synthes). Surgical procedures recommended by the manufacturer were followed. The level to receive the arthroplasty device (C56 in 5 specimens or $\mathrm{C} 4-5$ in 2 specimens) was confirmed with fluoroscopy. A standard discectomy was performed by a senior neurosurgical resident. The posterior longitudinal ligament (PLL) was resected in all cases. Disc replacement was performed with the appropriate instruments using a 5-mm height in all cases, which is consistent with the height most commonly used clinically for this device. ${ }^{20,29}$ Based on the intact disc height, no 6-mm height prostheses were considered appropriate. For width and depth, the device with the largest possible cross-sectional area to fit the anatomy was used. No additional measures were taken to ensure that the device-bone interface remained rigid other than the friction press-fit between device keel and bone.

Foraminotomy (step 3, both groups; Fig. 1B) was performed at a single level on the left side in all cases using a high-speed pneumatic drill (The Anspach Effort). Foraminotomies were performed on the left side to avoid touching optical markers, which were mounted on the right side. In a standardized approach for all specimens, a 5-mm burr was used to thin the medial half of the facet and a few millimeters of the lateral lamina. Once the drilling was complete, the Kerrison punch was used to remove the eggshell bone, lateral ligamentum flavum, and soft tissue to visualize the nerve from its origin through its distal course, as provided by removal of the medial $50 \%$ of the facet. ${ }^{13,15,23,30}$ The extent of resection was adequate to represent clinical- 

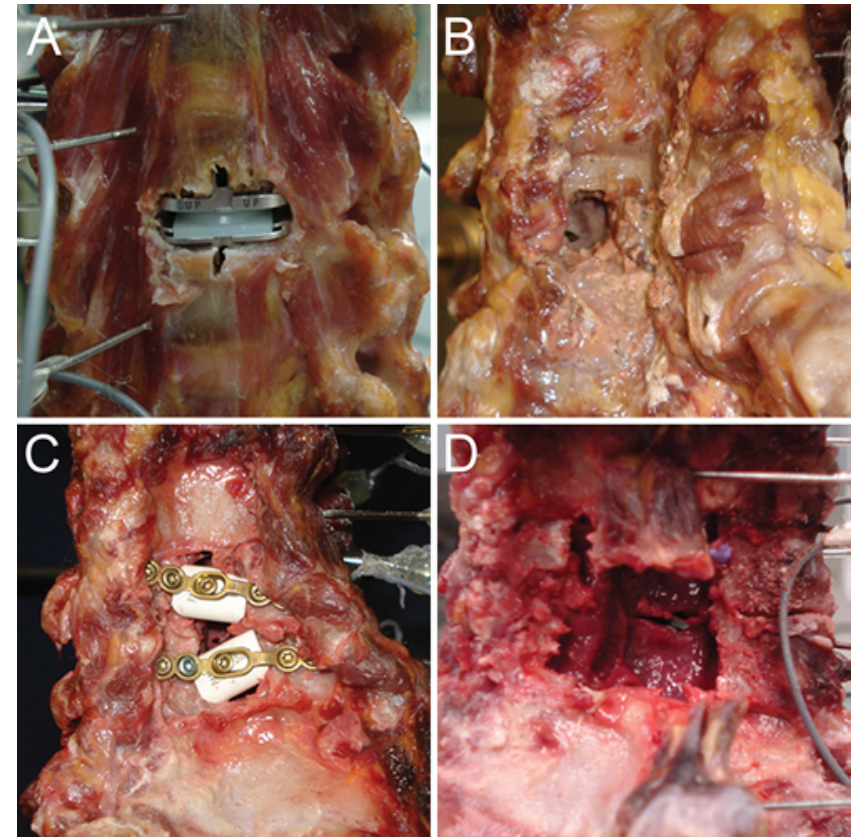

FIG. 1. Photographs of representative specimens demonstrating the surgical procedures studied. A: Anterior view showing ProDisc-C device positioned at the C5-6 disc space. B: Posterolateral view showing the extent of the foraminotomy. C: Posterolateral view showing the laminoplasty construct. D: Posterior view showing the extent of the laminectomy. Note that the transected PLL is visible across the empty spinal canal. Figure is available in color online only.

ly relevant decompression of the nerve, avoiding excessive lamina removal..$^{14,16}$

Laminoplasty (step 4, both groups; Fig. 1C) was performed using the ARCH system (DePuy Synthes). First, a greenstick fracture was created on the right side of the $\mathrm{C} 5$ and $\mathrm{C} 6$ laminae (C4 and $\mathrm{C} 5$ in 2 specimens) using the high-speed drill with a matchstick tip to cut a deep groove in the bone. On the left side, an osteotomy of the C5 and C6 (or C4 and C5) laminae was performed. As with the foraminotomy, left-sided procedures were performed to avoid contacting optical markers. Spacer size was chosen according to anatomy. Either $2.5 \times 4-$ or $2.5 \times 6-\mathrm{mm}$ screws were used to secure the spacer to the plate and to secure the plate to lamina/spinous process.

For laminectomy (step 5, both groups; Fig. 1D), the laminoplasty instrumentation was completely removed. Next, the right C5 and C6 laminae were drilled through using a high-speed drill with a small fluted bit, and the lamina and spinous process were removed.

\section{Biomechanical Testing}

Specimens were studied sequentially in two different loading apparatuses: a pure-moment flexibility apparatus and a physiological flexion-extension stiffness apparatus (Fig. 2). For pure-moment testing, a system of cables and pulleys imparts nondestructive, nonconstraining torques in conjunction with a standard servohydraulic test system (MTS Systems Corp.), as described previously. ${ }^{8,9}$ This type of loading is distributed evenly to each motion segment, regardless of its distance from the point of loading, which can

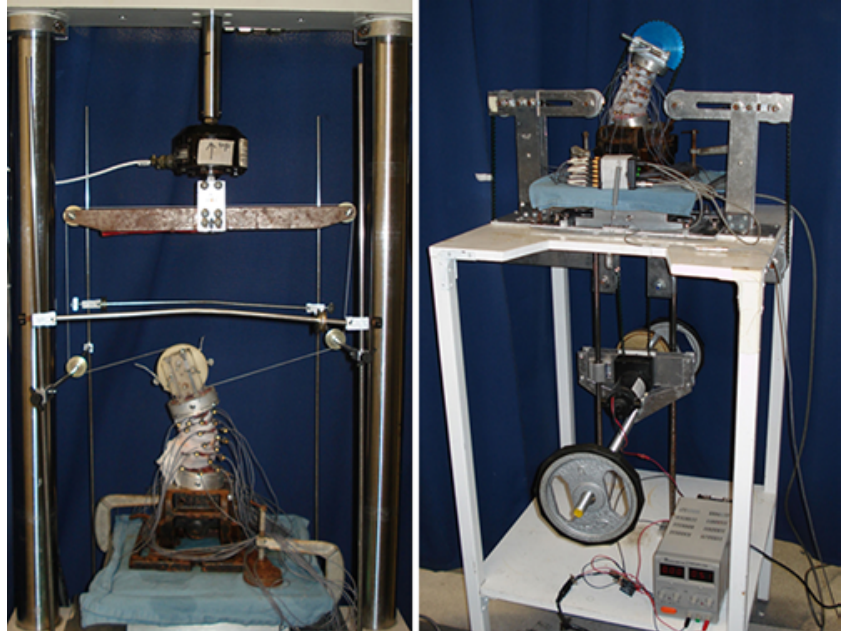

FIG. 2. Loading apparatuses used in the experiments. Left: Pure-moment apparatus: Adjustable pulleys are used in conjunction with a standard servohydraulic test frame, enabling two equal and opposite forces separated by a small distance (pure moment) to be applied through a looped string when the piston advances upward. Right: Flexion-compression apparatus: A stepper motor connected to the specimen with a heavy belt applies flexion or extension. Weights hung from the motor apply a constant compressive preload. Because of the orientation of the pulleys, the direction of the preload stays aligned with the axis of the specimen throughout movement. Figure is available in color online only.

be an indicator of specimen degradation during the course of testing. ${ }^{24}$ Loads of $1.5 \mathrm{Nm}$ maximum were applied to induce different types of motion. The change in normalized ROM at adjacent levels was comparable to the index level during resection in both groups (data not shown). Next, for flexion-extension loading, specimens were transferred to an apparatus in which a constant compressive preload of $70 \mathrm{~N}$ was applied via a notched belt looped over the specimen and supporting dead weights, as described previously. ${ }^{8,9}$ In each condition studied, movement was induced until specimens reached the same global angle (sum of all levels) that was previously achieved during pure-moment flexibility tests for that condition.

Three-dimensional specimen motion during flexibility and stiffness tests was determined using the Optotrak 3020 system (Northern Digital), which measures stereophotogrammetrically the three-dimensional displacement of infrared-emitting markers rigidly attached in a noncollinear arrangement to each vertebra. Custom software converted the marker coordinates to angles about each of the anatomical axes in terms of each vertebra's own coordinate system. ${ }^{10}$ Spinal angles were calculated using a technique that provides appropriate results for describing a joint's primary and coupled angular motion patterns. ${ }^{12}$ Angles were quantified at the index level as well as the adjacent rostral and caudal levels.

\section{Statistical Analysis}

From the raw data, several parameters were calculated. The angular ROM, LZ (zone of ligamentous laxity), and SZ (zone with ligaments in tension) were determined from load-deformation responses. ${ }^{11}$ Due to the nonconstraining nature of the pure-moment loading apparatus, an applied 

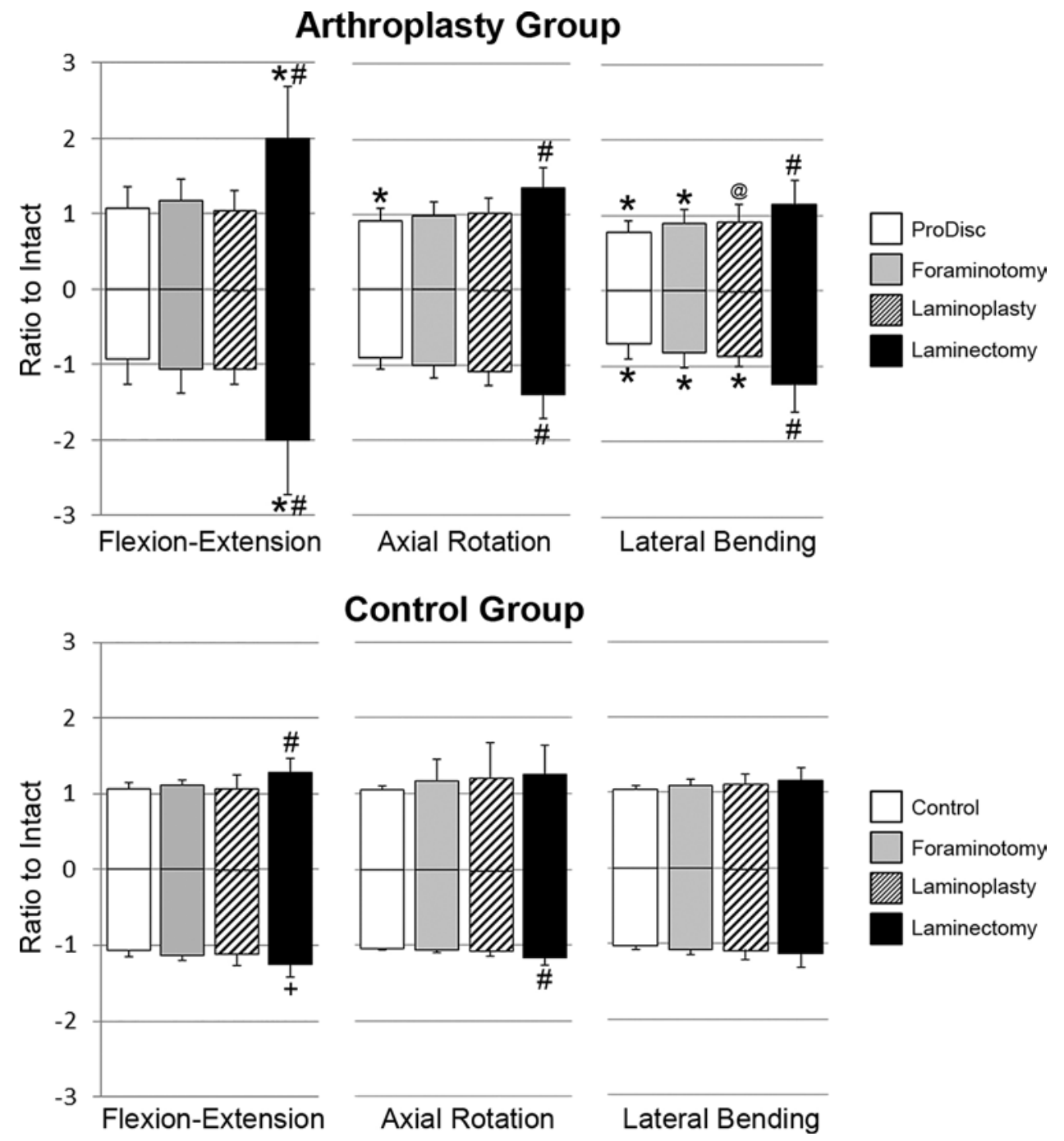

FIG. 3. Mean normalized angular ROM at the index level in each condition studied. Error bars show standard deviations. *Indicates significant difference of arthroplasty group (upper) compared to control group (lower). Significant within-group differences from intact specimens without posterior resection are indicated by \# (including foraminotomy and laminoplasty), @ (excluding foraminotomy), and + (including laminoplasty, but excluding foraminotomy).

moment may result in coupled motion out of the intended plane. Angular coupling factors (coupled ROM divided by primary ROM) were also assessed from data under a full load $(1.5 \mathrm{Nm})$. From stiffness tests, the location of the sagittal instantaneous axis of rotation (IAR) during flexionextension was determined in $0.5^{\circ}$ increments. ${ }^{7}$ Because flexion-extension motions typically exceeded $10^{\circ}$, this method gave a centrode of 20 or more finite centers of rotation for each test run. For comparison among specimens, the average of this centrode was calculated in the anteroposterior and rostrocaudal directions, and position was normalized based on the size of the specimen. These parameters were all quantified at the index level.

The data were statistically analyzed using nonpaired 2-tailed Student t-tests to determine whether parameters in the control group differed from the corresponding parameters in the arthroplasty group. Repeated-measures analysis of variance (RM-ANOVA) followed by HolmSidak tests were used to assess whether there were signifi- cant differences among conditions within each group. In these statistical tests, RM-ANOVA was first run to determine whether any significant difference existed between any two conditions. If RM-ANOVA proved significant ( $\mathrm{p}$ $<0.05$ ), it was followed by Holm-Sidak tests to identify which pairs of conditions differed; if it was not significant, Holm-Sidak tests were not run. To minimize the effect of specimen variability, data were normalized, where the value of a given parameter was divided by the corresponding value for the same specimen in the normal condition.

\section{Results}

\section{Range of Motion, Lax Zone, and Stiff Zone}

During flexion and extension, mean angular ROM, LZ, and SZ after arthroplasty were maintained and were not significantly different from those of controls (Figs. 3-5). During left axial rotation, ROM was reduced by $13 \%$ compared to controls, and LZ was reduced by $33 \%$ in overall 


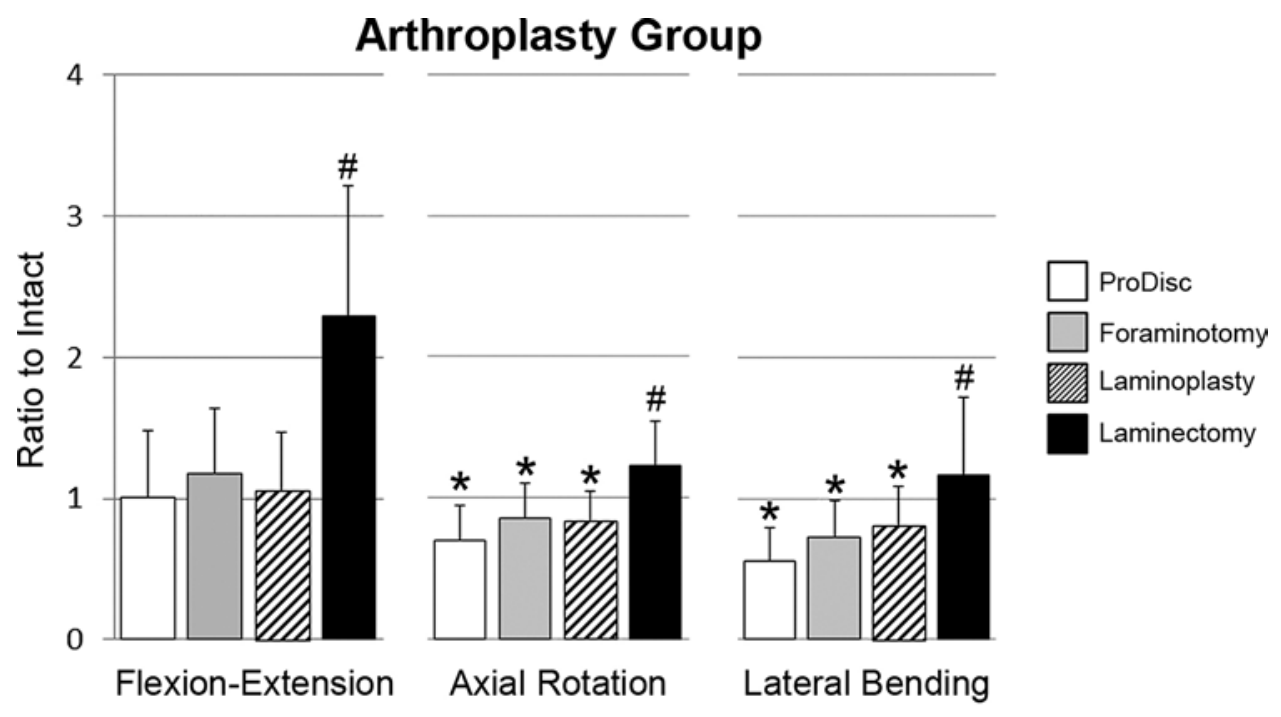

\section{Control Group}

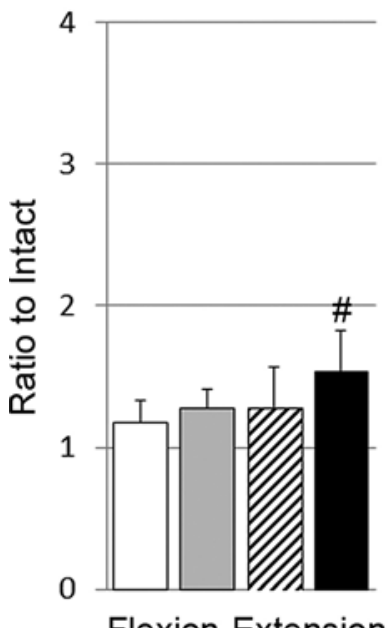

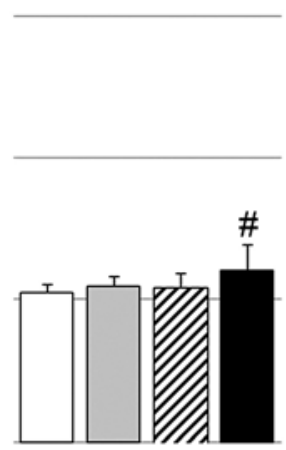

Axial Rotation

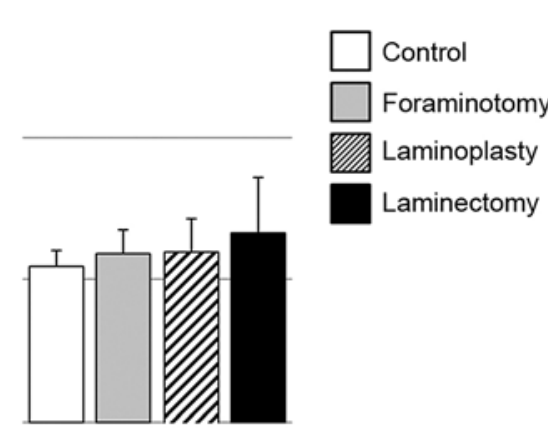

Lateral Bending

FIG. 4. Mean normalized angular LZ at the index level in each condition studied. Error bars show standard deviations. *Indicates significant difference of arthroplasty group (upper) compared to control group (lower). Significant within-group differences from intact specimens without posterior resection are indicated by \# (including foraminotomy and laminoplasty).

axial rotation. In lateral bending, ROM was reduced by $28 \%$ and LZ was reduced by $48 \%$, compared to controls. In contrast, SZ demonstrated a $61 \%$ and $39 \%$ increase over control specimens during axial rotation and left lateral bending, respectively. These reductions in LZ and ROM and increases in SZ were significantly greater in the arthroplasty group than in the control group $(\mathrm{p}<0.05)$.

Sequential foraminotomy, laminoplasty, and laminectomy altered the biomechanics of these specimens to varying degrees. During flexion and extension, mean angular ROM and SZ of the arthroplasty group were comparable to those of the control specimens following foraminotomy and laminoplasty, but not after laminectomy. Following laminectomy in the arthroplasty group, angular ROM was increased by $57 \%$ in flexion and extension, and SZ was increased by $35 \%$ in flexion only; these increases in ROM and SZ were significantly greater than those of the control group ( $\mathrm{p}<0.05)$. The $\mathrm{LZ}$ was comparable to that of controls following sequential resections, although flexion and extension approached significance following laminectomy.

During axial rotation in the arthroplasty group, mean angular ROM was maintained following sequential resections relative to that of controls. In comparison with that in intact specimens, LZ in arthroplasty specimens was reduced by $21 \%$ following foraminotomy and by $23 \%$ following laminoplasty. The LZ of arthroplasty specimens undergoing laminectomy was similar to that of intact controls. In comparison to that in the control specimens, SZ was significantly increased by $50 \%$ following foraminotomy, $78 \%$ following laminoplasty, and $81 \%$ following laminectomy $(\mathrm{p}<0.05)$.

During lateral bending, the mean angular ROM of the arthroplasty group, compared to controls, was significantly reduced by $20 \%$ following foraminotomy; during left lateral bending, it was reduced by $21 \%$ following laminoplasty $(\mathrm{p}<0.05)$. Angular ROM of the arthroplasty specimens undergoing laminectomy was similar to that 

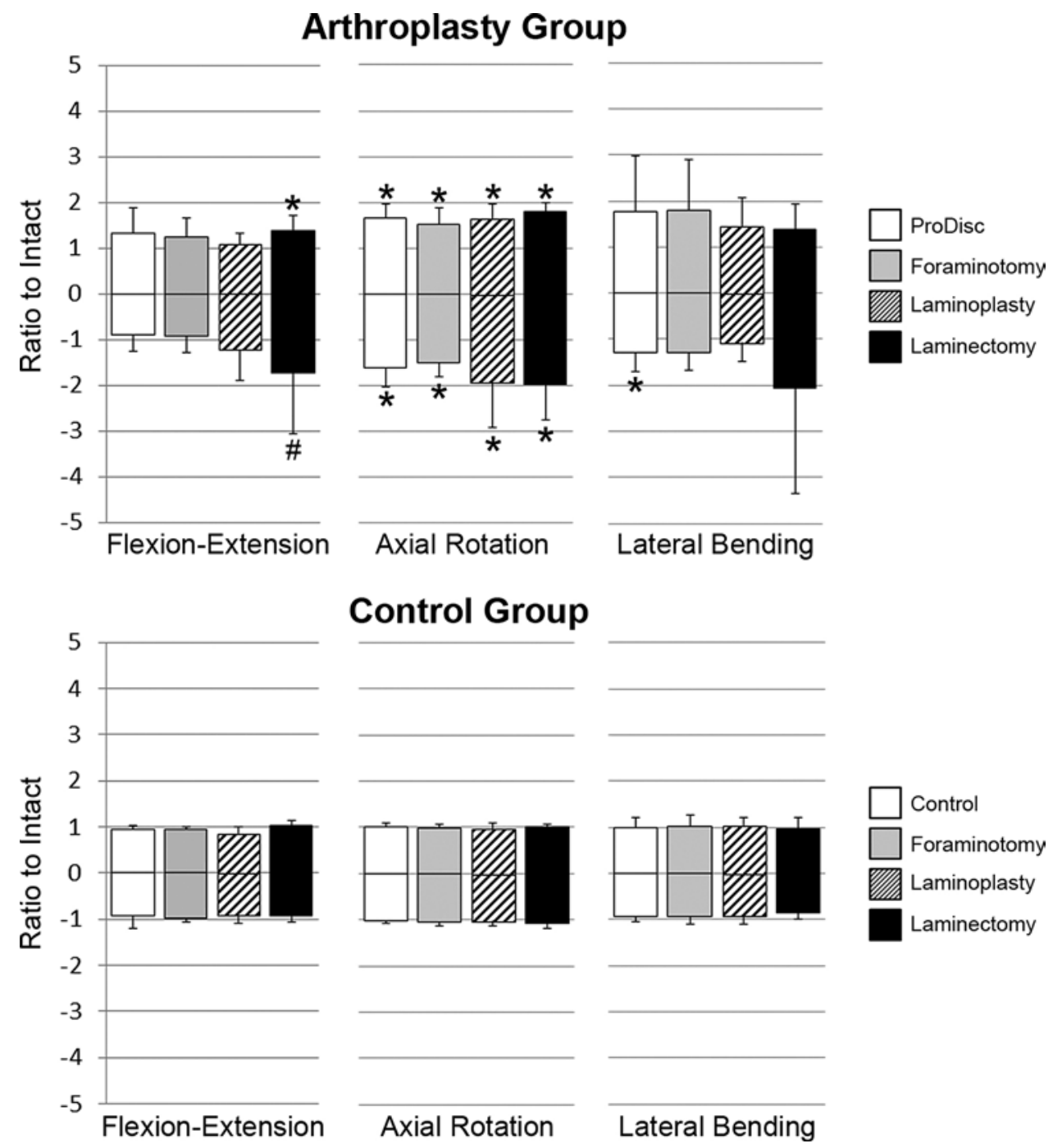

Control Group

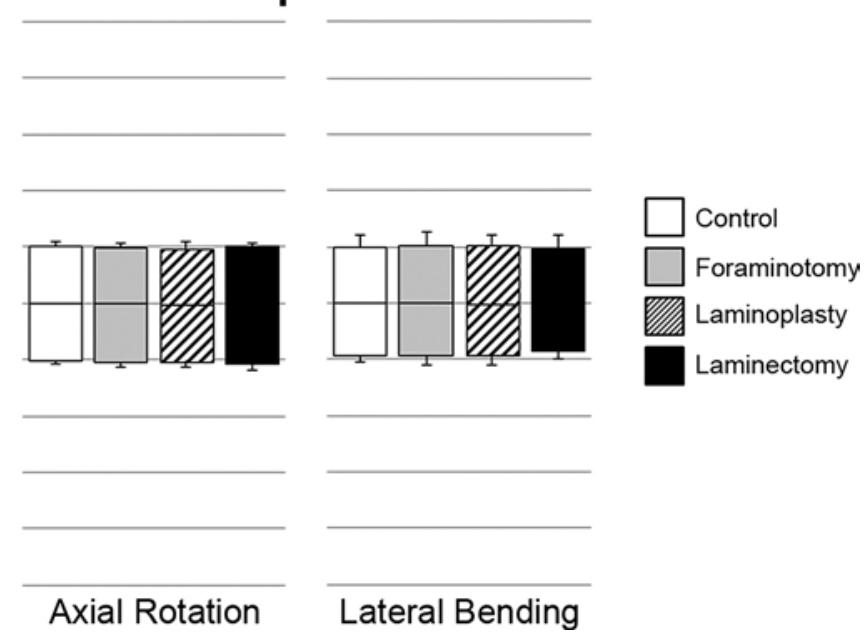

FIG. 5. Mean normalized angular SZ at the index level in each condition studied. Error bars show standard deviation. *Indicates significant difference of arthroplasty group (upper) compared to control group (lower). Significant within-group differences from intact specimens without posterior resection are indicated by \# (including foraminotomy, but not laminoplasty).

of intact controls. Moreover, LZ, compared to that in the control specimens, was significantly reduced by $39 \%$ following foraminotomy and by $32 \%$ following laminoplasty ( $\mathrm{p}<0.05$ ); LZ was similar to that of the controls following laminectomy. In comparison, SZ was maintained following sequential resections relative to controls.

\section{Within-Group Comparisons}

When comparing sequential resections within the experimental or control group, there was no significant effect of foraminotomy and laminoplasty on ROM, LZ, or SZ during any of the tested motions compared to either each other or the control state without any posterior resections. The only exception was significantly increased $\mathrm{ROM}$ during right lateral bending following laminoplasty in the arthroplasty group $(\mathrm{p}<0.05)$. In contrast, ROM and LZ following laminectomy in the arthroplasty group were significantly greater than those parameters in all other tested conditions measured following the earlier sequential resections $(\mathrm{p}<0.05)$. The SZ following laminectomy in the arthroplasty group was significantly increased in extension only relative to that after foraminotomy and after ProDisc-C insertion ( $\mathrm{p}<0.05)$, but not after laminoplasty.

The motion induced following laminectomy was less extensive than that following the previous posterior resections in the control group, but significant increases were still demonstrated in ROM during flexion and right axial rotation and in LZ during flexion-extension and axial rotation $(\mathrm{p}<0.05)$. Mean ROM during extension was significantly increased relative to that parameter in the control state and after laminoplasty, but not after foraminotomy ( $\mathrm{p}$ $<0.05$ ). There was no significant increase in SZ following laminectomy in any motions tested.

\section{Lateral Bending During Axial Rotation}

At the index level, the coupled lateral bending per degree of primary axial rotation was normally about $0.6^{\circ}$. In both groups, this ratio decreased (relative to normal) after arthroplasty and sequential resections (Fig. 6A and B). The decrease was more variable in the arthroplasty group 
Arthroplasty Group
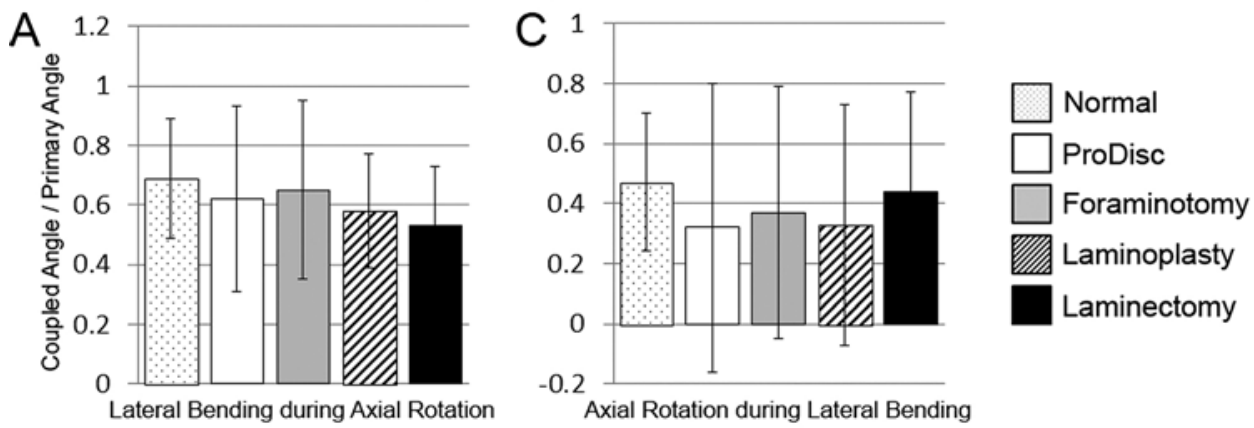

\section{Control Group}
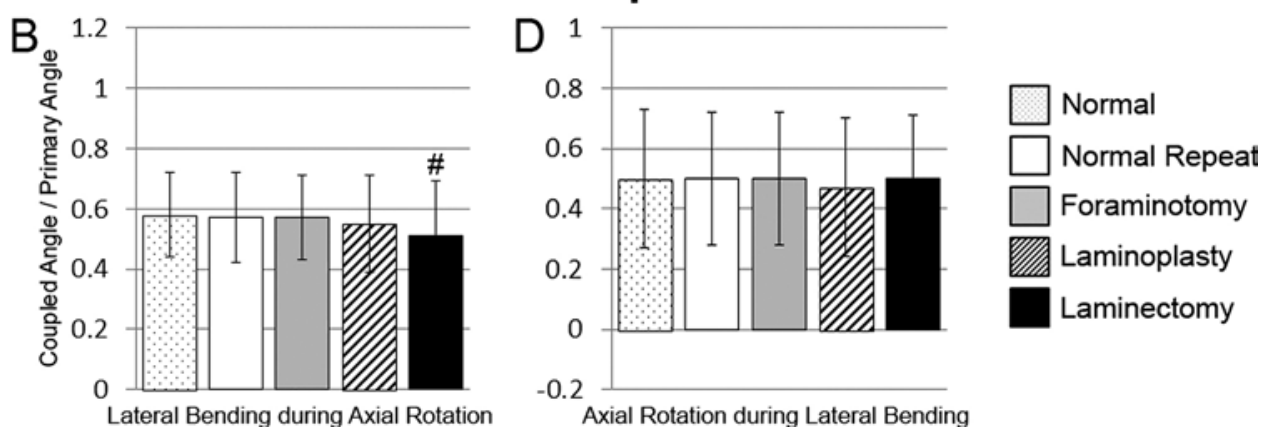

FIG. 6. Coupled lateral bending per degree of primary axial rotation ( $A$ and $\mathbf{B}$ ) and coupled axial rotation per degree of primary lateral bending ( $C$ and $\mathbf{D})$ at the index level. Error bars show standard deviations. Significant within-group differences from intact specimens without posterior resection are indicated by \# (including foraminotomy and laminoplasty).

than in the control group, although there was no significant difference between groups. Laminectomy caused the greatest decrease in the coupling ratio in both groups; in the control group, laminectomy caused the coupling ratio to be significantly decreased relative to normal, laminotomy, laminoplasty, and foraminotomy $(\mathrm{p}<0.05)$.

\section{Axial Rotation During Lateral Bending}

The coupled axial rotation per degree of primary lateral bending was normally about $0.5^{\circ}$. In the arthroplasty group, this ratio decreased (relative to normal) after arthroplasty and sequential resections; in the control group, this ratio stayed fairly constant (Fig. 6C and D). The ratio was more variable in the arthroplasty group. There was no significant difference among conditions either between or within groups.

\section{Axis of Rotation}

Normally, the IAR was located in the posterior twothirds of the vertebral body below the disc space (Fig. 7). In both groups, the location of the IAR was similar. The different stages of resection caused smaller shifts in the position of the IAR at later stages than the initial shift observed with artificial disc insertion. The shift due to disc insertion totaled $5.5 \pm 4.3 \mathrm{~mm}$, averaging $3.0 \pm 4.2 \mathrm{~mm}$ of anterior shift and $0.6 \pm 5.1 \mathrm{~mm}$ of rostral shift. Further shifts averaged less than $1.1 \mathrm{~mm}$ in any direction (or less than $2.4 \mathrm{~mm}$ total). In contrast, in the control group, the largest shift relative to normal in the rostrocaudal or anteroposterior direction, even after laminoplasty or laminectomy, was $0.8 \pm 2.3 \mathrm{~mm}(2.0 \pm 1.5 \mathrm{~mm}$ total shift $)$.

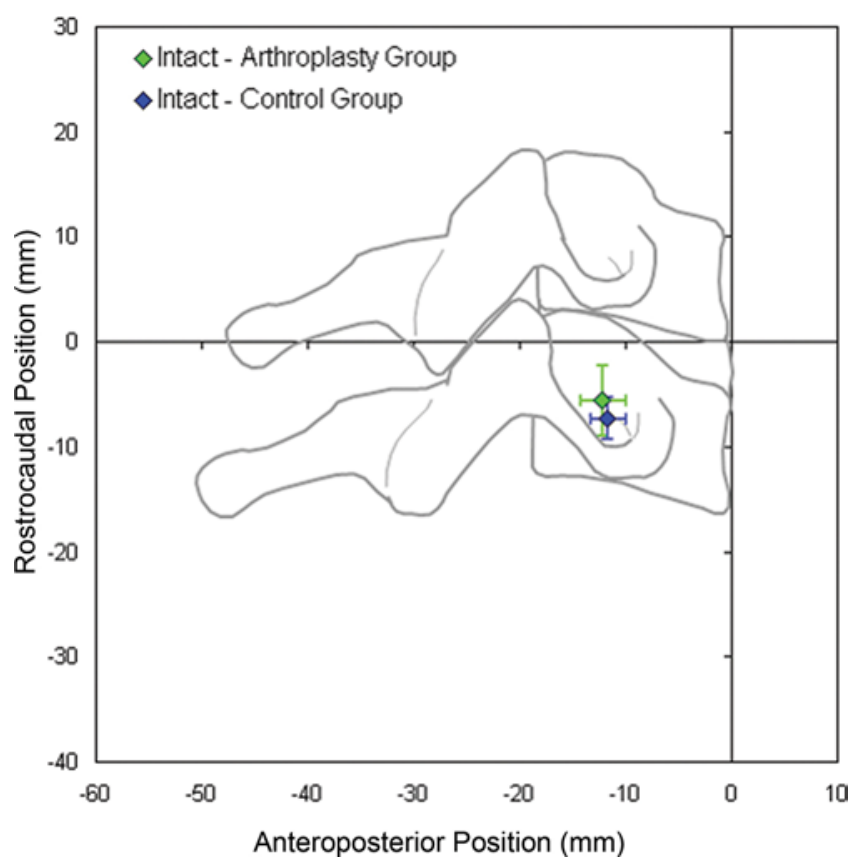

FIG. 7. Mean location of the axis of rotation at the index level in the sagittal plane in the intact condition for the arthroplasty group and the control group. Error bars show standard deviation among 7 specimens per group. Figure is available in color online only. 


\section{Discussion}

Numerous clinical studies evaluating the ProDisc-C have demonstrated excellent clinical outcomes, as well as the maintenance of preoperative biomechanics. ${ }^{17,21,22,32}$ However, a subset of patients will inevitably demonstrate persistent or late recurrent symptoms following CA, and risks related to combining arthroplasty with subsequent posterior procedures are unclear. For residual or recurrent radiculopathy or new central spinal stenosis, anterior revision surgery will require removal of the disc replacement, followed by a fusion in many cases. Thus, understanding the biomechanical consequences of graded posterior decompressive procedures may reveal an alternative surgical option for nerve root or spinal cord decompression in the setting of previous cervical disc replacement. The objective of this study was to understand the effects of unilateral foraminotomy, laminoplasty, and laminectomy on cervical intervertebral motion after CA.

The ProDisc-C device was selected for study for several reasons. Although this device was recently removed from clinical usage, it has a long clinical history as one of the first CA devices approved by the FDA in 2007. There is robust literature on its clinical use and biomechanical profile, which allows for effective interpretation of the present study's results. Additionally, patients with a ProDisc-C may have had their device for 10 years or longer, and this population may begin to develop further cervical disease; thus, posterior spinal decompression may need to be considered, highlighting the relevance of this study. Finally, the ball-and-socket design continues to be widely used in arthroplasty devices; thus, our findings may be generalizable to other devices on the market.

\section{Biomechanical Characteristics}

Normalized ROM and LZ after arthroplasty were comparable to those of controls during flexion and extension. Physiological ROM was well maintained by insertion of the arthroplasty device. During axial rotation and lateral bending, both ROM and LZ were reduced compared to control specimens. These findings match previous observations from in vitro studies, which have demonstrated that the ProDisc-C tends to limit lateral bending and (to a lesser extent) axial rotation while matching the intact flexion and extension ROM. ${ }^{8}$

With sequential posterior element resections, the ROM and LZ increased by a similar magnitude in both groups. When compared between groups, some of the differences that were introduced with disc insertion were maintained after foraminotomy or laminoplasty, particularly the relatively reduced amount of lateral bending. In contrast, laminectomy had a much greater effect on the arthroplasty group. In the control group, the magnitude of increase in ROM or LZ after laminectomy was similar to the magnitude of increase following earlier steps. In the arthroplasty group, the flexion-extension ROM and LZ from laminoplasty to laminectomy increased by $90 \%$ and $116 \%$, respectively. In comparison, the normalized ROM and LZ in the control group increased by only $16 \%$ and $19 \%$, respectively, from laminoplasty to laminectomy.

The SZ, unlike LZ and ROM, was generally increased in all directions of loading after arthroplasty. This response indicates a more flexible, gradual response to loading with arthroplasty due to less friction of the joint compared to the intact disc. The SZ changes with sequential resections were similarly greater in the arthroplasty group and demonstrated greater variability. Such a large discrepancy in variance between groups was not observed with ROM or LZ. Thus, arthroplasty seems to have an inconsistent effect on the elastic response of the joint and a more consistent effect on the limits to motion.

The angular coupling pattern of lateral bending during axial rotation after ProDisc-C insertion was slightly decreased. Posterior resections showed further loss of the coupling, mimicking the response in the control group. The control group's gradual decline of coupling with increased posterior resection reached significance after laminectomy, indicating the importance of the posterior elements in guiding this coupling motion. The larger variance in the coupling of the arthroplasty group suggests that the coupling after arthroplasty is inconsistent and may be technique or specimen dependent. For coupled axial rotation during lateral bending, there was not a significant drop-off in coupling in the control group with increasing resection, suggesting that the integrity of the posterior elements is less important for axial rotation during lateral bending than for lateral bending during axial rotation. Increased variance was again demonstrated in the arthroplasty group, further suggesting inconsistent biomechanics.

The IAR was similarly positioned in both groups in intact specimens. Artificial disc insertion caused much larger shifts in the position of the IAR than any subsequent resection and was also associated with greater variance in the position of the IAR. Thus, arthroplasty has a greater effect on segment kinematics than any of the resections. Arthroplasty caused the IAR to shift mainly in the anterior direction rather than rostrally or caudally. This pattern of shift relates to the design of the ball-and-socket prosthesis, which is known to shift the center of rotation anteriorly. ${ }^{19}$ Since the ProDisc-C is a ball-and-socket device with a fixed center of rotation, it is likely that even a well-positioned device with maximum endplate coverage will result in an anterior shift in the IAR.

\section{Clinical Relevance}

Posterior decompression has the potential to induce cervical spine instability, depending on the extent of resection. ${ }^{5,31}$ In a cadaveric model without arthroplasty, Brown et al. reported that significant instability could only be demonstrated after sectioning the posterior ligaments, both facet joints, and the PLL. ${ }^{4}$ Recently, a number of cadaveric studies have begun to address the biomechanics of CA following progressive posterior decompression. Kikkawa et al. demonstrated that, after single-level CA utilizing a metal-on-polyurethane ball-and-socket CA device, multilevel laminectomy, compared to multilevel laminoplasty, increased ROM. ${ }^{18}$ Bevevino et al. demonstrated that bilateral foraminotomy in cervical spine specimens implanted with a metal-on-metal, ball-in-trough CA device did not significantly increase segmental ROM. ${ }^{2}$

Roberto et al. evaluated the effects of PLL resection, unilateral and bilateral foraminotomy (50\% facet joint re- 
section), and laminectomy on cervical stability in a spondylotic model utilizing the ProDisc-C. ${ }^{25}$ Progressive resections led to minor increases in sagittal rotation ROM, with a substantial $57 \%$ increase following laminectomy. However, these values were within normative physiological limits; thus, the authors concluded that sequential posterior resection did not result in clinically relevant spinal instability. These authors focused solely on a flexion and extension paradigm, and they also used older specimens (mean age 78 years).

In another biomechanical model utilizing the ProDisc$\mathrm{C}$, Brody et al. demonstrated that a unilateral foraminotomy did not result in a significantly increased ROM. ${ }^{3}$ Bilateral foraminotomies increased ROM, but within physiological ranges. However, bilateral foraminotomies in the presence of a full laminectomy were associated with segmental ROM at the upper limits of published normative data, suggesting nonphysiological motion. The largest increase in segmental ROM followed laminectomy $(32.5 \%$ increase in flexion-extension). Thus, these authors advised against a full laminectomy following CA. The study was limited by its experimental design, such that changes in ROM in the arthroplasty model were compared to an intact specimen that did not undergo sequential posterior element resections.

Although laminectomy was the final endpoint in these studies, both Roberto et al. ${ }^{25}$ and Brody et al. ${ }^{3}$ performed a bilateral foraminotomy, whereas our protocol involved a laminoplasty as the penultimate procedure, which may affect the biomechanics and thus data interpretation. Interestingly, we reported a $90 \%$ increase in flexion-extension in the arthroplasty group from laminoplasty to laminectomy (compared to $16 \%$ in the control group), which is of greater magnitude than rates in previously published studies. The differences from our findings are likely attributable to differences in testing protocols and data analysis, as well as in surgical technique, setup of the load application, or the tested specimens. Regardless, the current published literature uniformly raises the concern of increased segmental ROM following laminectomy in an in vitro arthroplasty model.

\section{Study Limitations}

Cadaveric studies are inherently limited given their in vitro design, and any extrapolation to in vivo situations must be made with caution. In particular, the current models cannot account for the long-term use of a CA device or device integration into host tissue and under normal physiological stressors. That is, after bony ingrowth of the vertebral body into contact surfaces of the artificial disc, the device may pivot differently because stresses are transferred to the device articulations instead of the device-bone interface. These differences in cervical spine motion between immediate postoperative and fully healed CA patients are unknown. Since specimens were repeatedly tested with different degrees of resection, there could have been progressive CA implant loosening on successive tests, making steps tested later appear to have greater motion than would occur in vivo. The comparison to a control group accounts for progressive loosening of soft tissues with repeat tests but does not account for this factor. It was assumed that friction between midline keel and bone maintained a rigid interface.

In addition, it was important to use normalized values in these comparisons since the arthroplasty group had greater inherent ROM and LZ than the control group. Using nonnormalized data would not reflect true differences between groups. It is unclear whether the differences in ROM and LZ were related to the finding that the control group showed a trend of higher BMD than the CA group. This study was also limited by the use of older specimens (mean age 55 years). As CA is considered a motion-preserving rather than a motion-restorative procedure, ideal operative candidates are younger adults with relatively preserved segmental motion kinetics. Finally, because of limited specimen availability and cost, sample numbers were relatively low, which can lead to false-negative findings.

\section{Conclusions}

There was a relatively small change in ROM, LZ, SZ, and kinematic measures in either the arthroplasty or the control group after foraminotomy and laminoplasty. Therefore, foraminotomy and laminoplasty did not induce the instability that would otherwise be expected after arthroplasty. Both foraminotomy and laminoplasty appeared suitable in the setting of prior insertion of the ProDisc-C.

After laminectomy, the increased instability (ROM and LZ) was substantially larger than that following previous steps and that introduced by laminectomy without arthroplasty. Thus, laminectomy alone should be approached with caution in the setting of previous CA, as there is potential for instability, particularly during flexion and extension.

\section{References}

1. Baaj AA, Uribe JS, Vale FL, Preul MC, Crawford NR: History of cervical disc arthroplasty. Neurosurg Focus 27(3):E10, 2009

2. Bevevino AJ, Lehman RA Jr, Kang DG, Gwinn DE, Dmitriev AE: The effect of cervical posterior foraminotomy on segmental range of motion in the setting of total disc arthroplasty. Spine (Phila Pa 1976) 39:1572-1577, 2014

3. Brody MJ, Patel AA, Ghanayem AJ, Wojewnik B, Carandang G, Havey RM, et al: The effect of posterior decompressive procedures on segmental range of motion after cervical total disc arthroplasty. Spine (Phila Pa 1976) 39:1558-1563, 2014

4. Brown T, Reitman CA, Nguyen L, Hipp JA: Intervertebral motion after incremental damage to the posterior structures of the cervical spine. Spine (Phila Pa 1976) 30:E503-E508, 2005

5. Clarke MJ, Ecker RD, Krauss WE, McClelland RL, Dekutoski MB: Same-segment and adjacent-segment disease following posterior cervical foraminotomy. J Neurosurg Spine 6:5-9, 2007

6. Crawford NR: Analysis: in vitro biomechanical construct tests evaluating cervical arthroplasty. World Spine J 1:7-13, 2006

7. Crawford NR: Technical note: Determining and displaying the instantaneous ax is of rotation of the spine. World Spine J 1:53-56, 2006

8. Crawford NR, Baek S, Sawa AG, Safavi-Abbasi S, Sonntag VK, Duggal N: Biomechanics of a fixed-center of rotation cervical intervertebral disc prosthesis. Int J Spine Surg 6:34-42, 2012

9. Crawford NR, Brantley AG, Dickman CA, Koeneman EJ: 
An apparatus for applying pure nonconstraining moments to spine segments in vitro. Spine (Phila Pa 1976) 20:20972100,1995

10. Crawford NR, Dickman CA: Construction of local vertebral coordinate systems using a digitizing probe. Technical note. Spine (Phila Pa 1976) 22:559-563, 1997

11. Crawford NR, Peles JD, Dickman CA: The spinal lax zone and neutral zone: measurement techniques and parameter comparisons. J Spinal Disord 11:416-429, 1998

12. Crawford NR, Yamaguchi GT, Dickman CA: A new technique for determining 3-D joint angles: the tilt/twist method. Clin Biomech (Bristol, Avon) 14:153-165, 1999

13. Cusick JF, Yoganandan N, Pintar F, Myklebust J, Hussain $\mathrm{H}$ : Biomechanics of cervical spine facetectomy and fixation techniques. Spine (Phila Pa 1976) 13:808-812, 1988

14. Epstein NE: Open laminoforaminotomy: a lost art? Surg Neurol Int 6 (Suppl 24):S600-S607, 2015

15. Hong-Wan N, Ee-Chon T, Qing-Hang Z: Biomechanical effects of C2-C7 intersegmental stability due to laminectomy with unilateral and bilateral facetectomy. Spine (Phila Pa 1976) 29:1737-1746, 2004

16. Jagannathan J, Sherman JH, Szabo T, Shaffrey CI, Jane JA: The posterior cervical foraminotomy in the treatment of cervical disc/osteophyte disease: a single-surgeon experience with a minimum of 5 years' clinical and radiographic followup. J Neurosurg Spine 10:347-356, 2009

17. Janssen ME, Zigler JE, Spivak JM, Delamarter RB, Darden BV II, Kopjar B: ProDisc-C total disc replacement versus anterior cervical discectomy and fusion for single-level symptomatic cervical disc disease: seven-year follow-up of the prospective randomized U.S. Food and Drug Administration investigational device exemption study. J Bone Joint Surg Am 97:1738-1747, 2015

18. Kikkawa J, Cunningham BW, Shirado O, Hu N, McAfee PC, Oda $\mathrm{H}$ : Multidirectional flexibility of the spine following posterior decompressive surgery after single-level cervical disc arthroplasty: an in vitro biomechanical investigation. Spine (Phila Pa 1976) 35:E1465-E1471, 2010

19. Kowalczyk I, Lazaro BC, Fink M, Rabin D, Duggal N: Analysis of in vivo kinematics of 3 different cervical devices: Bryan disc, ProDisc-C, and Prestige LP disc. J Neurosurg Spine 15:630-635, 2011

20. Lazaro BC, Yucesoy K, Yuksel KZ, Kowalczyk I, Rabin D, Fink M, et al: Effect of arthroplasty design on cervical spine kinematics: analysis of the Bryan Disc, ProDisc-C, and Synergy disc. Neurosurg Focus 28(6):E6, 2010

21. Malham GM, Parker RM, Ellis NJ, Chan PG, Varma D: Cervical artificial disc replacement with ProDisc-C: clinical and radiographic outcomes with long-term follow-up. J Clin Neurosci 21:949-953, 2014

22. Murrey D, Janssen M, Delamarter R, Goldstein J, Zigler J, Tay B, et al: Results of the prospective, randomized, controlled multicenter Food and Drug Administration investigational device exemption study of the ProDisc-C total disc replacement versus anterior discectomy and fusion for the treatment of 1-level symptomatic cervical disc disease. Spine J 9:275-286, 2009

23. Nowinski GP, Visarius H, Nolte LP, Herkowitz HN: A biomechanical comparison of cervical laminaplasty and cervical laminectomy with progressive facetectomy. Spine (Phila Pa 1976) 18:1995-2004, 1993
24. Panjabi MM: Biomechanical evaluation of spinal fixation devices: I. A conceptual framework. Spine (Phila Pa 1976) 13:1129-1134, 1988

25. Roberto RF, McDonald T, Curtiss S, Neu CP, Kim K, Pennings F: Kinematics of progressive circumferential ligament resection (decompression) in conjunction with cervical disc arthroplasty in a spondylotic spine model. Spine (Phila Pa 1976) 35:1676-1683, 2010

26. Safavi-Abbasi S, Reyes PM, Abjornson C, Crawford NR: Feasibility and biomechanics of multilevel arthroplasty and combined cervical arthrodesis and arthroplasty. Clin Spine Surg 29:E522-E531, 2016

27. Sekhon LH, Sears W, Duggal N: Cervical arthroplasty after previous surgery: results of treating 24 discs in 15 patients. $\mathbf{J}$ Neurosurg Spine 3:335-341, 2005

28. Snyder JT, Tzermiadianos MN, Ghanayem AJ, Voronov LI, Rinella A, Dooris A, et al: Effect of uncovertebral joint excision on the motion response of the cervical spine after total disc replacement. Spine (Phila Pa 1976) 32:2965-2969, 2007

29. Staudt MD, Das K, Duggal N: Does design matter? Cervical disc replacements under review. Neurosurg Rev 41:399-407, 2018

30. Voo LM, Kumaresan S, Yoganandan N, Pintar FA, Cusick JF: Finite element analysis of cervical facetectomy. Spine (Phila Pa 1976) 22:964-969, 1997

31. Zdeblick TA, Zou D, Warden KE, McCabe R, Kunz D, Vanderby R: Cervical stability after foraminotomy. A biomechanical in vitro analysis. J Bone Joint Surg Am 74:22-27, 1992

32. Zigler JE, Delamarter R, Murrey D, Spivak J, Janssen M: ProDisc-C and anterior cervical discectomy and fusion as surgical treatment for single-level cervical symptomatic degenerative disc disease: five-year results of a Food and Drug Administration study. Spine (Phila Pa 1976) 38:203-209, 2013

\section{Disclosures}

Dr. Crawford is an employee of and has direct stock ownership in Globus Medical. Dr. Duggal is a consultant for Synergy Disc Replacement Inc., has received clinical or research support from DePuy Synthes for the study described, and has received support from Medtronic for non-study-related clinical or research effort.

\section{Author Contributions}

Conception and design: Duggal, Crawford. Acquisition of data: Rabin, Baaj, Crawford. Analysis and interpretation of data: all authors. Drafting the article: all authors. Critically revising the article: Duggal, Staudt, Crawford. Reviewed submitted version of manuscript: Duggal, Staudt, Crawford. Approved the final version of the manuscript on behalf of all authors: Duggal. Statistical analysis: Staudt, Rabin, Baaj. Administrative/technical/material support: Duggal, Crawford. Study supervision: Duggal, Crawford.

\section{Correspondence}

Neil Duggal: Western University, London, ON, Canada. neil. duggal@lhsc.on.ca. 